\section{Eye Loss by Exogenous Endophthalmitis Following Anti- Tumor Necrosis Factor Therapy: A Report of 3 Cases}

\section{To the Editor:}

Infectious endophthalmitis is a serious infection of intraocular fluids and tissues, which often leads to loss of vision ${ }^{1}$. It can be classified as exogenous or endogenous according to the mechanism of infection. Endogenous endophthalmitis results from hematogenous spread of organisms to the eye, whereas exogenous endophthalmitis occurs due to direct infection of the eye following surgery or penetrating trauma ${ }^{2}$. Anti-tumor necrosis factor- $\alpha$ (TNF- $\alpha$ ) drugs are a highly effective treatment for rheumatoid arthritis (RA) and ankylosing spondylitis (AS) but increase the rate of soft tissue and skin infections ${ }^{3}$. However, only a few cases of severe eye infection have been reported ${ }^{4-8}$. We describe 3 patients who developed exogenous endophthalmitis during treatment with anti-TNF- $\alpha$.
Patient 1. A 36-year-old woman had a history of 11 years of erosive RA. She had right facial palsy secondary to facial trauma, leading to difficulty completely closing her right eye. Her RA remained active despite conventional disease modifying antirheumatic drugs (DMARD). Infliximab (3 $\mathrm{mg} / \mathrm{kg}$ ) was therefore started in January 2003, together with methotrexate (MTX; $15 \mathrm{mg} / \mathrm{wk}$ ) and prednisolone $(10 \mathrm{mg} / \mathrm{day})$. This led to a marked improvement of RA. In May 2004, 10 days after the eleventh infusion, she complained of an acute pain in her right eye associated with vision loss. She had a red eye upon examination, associated with a corneal ulceration and hypopyon. Infliximab was discontinued and a vitreous biopsy was performed. Gram staining of vitreous fluid was positive for Pseudomonas aeruginosa. Despite intravenous and intraocular antimicrobial therapy, she developed a corneal opacification leading to complete loss of vision (no light perception; Figure 1). She underwent further evisceration and received an eye prosthesis.

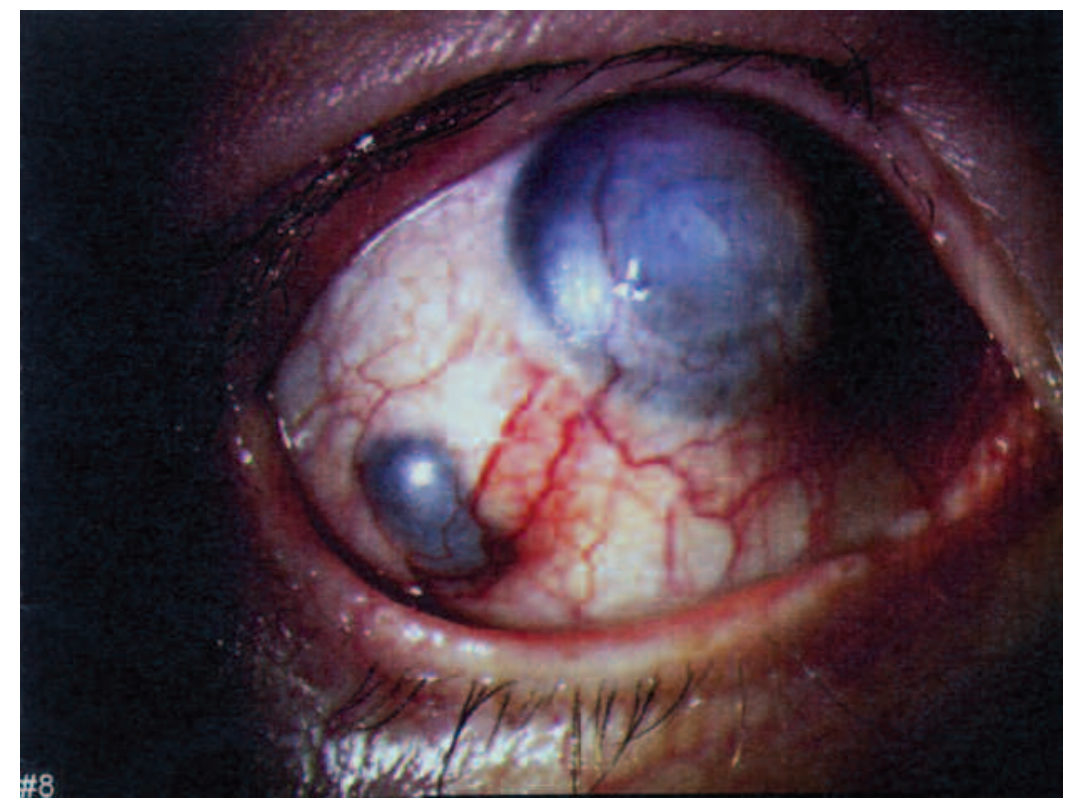

Figure 1. Slit-lamp examination of Patient 1,3 months after emergency corneal patch graft and antibiotic treatment. Note (above right) an area of scleromalacia and corneal opacification with neovessels suggesting severe previous infectious ocular disease.

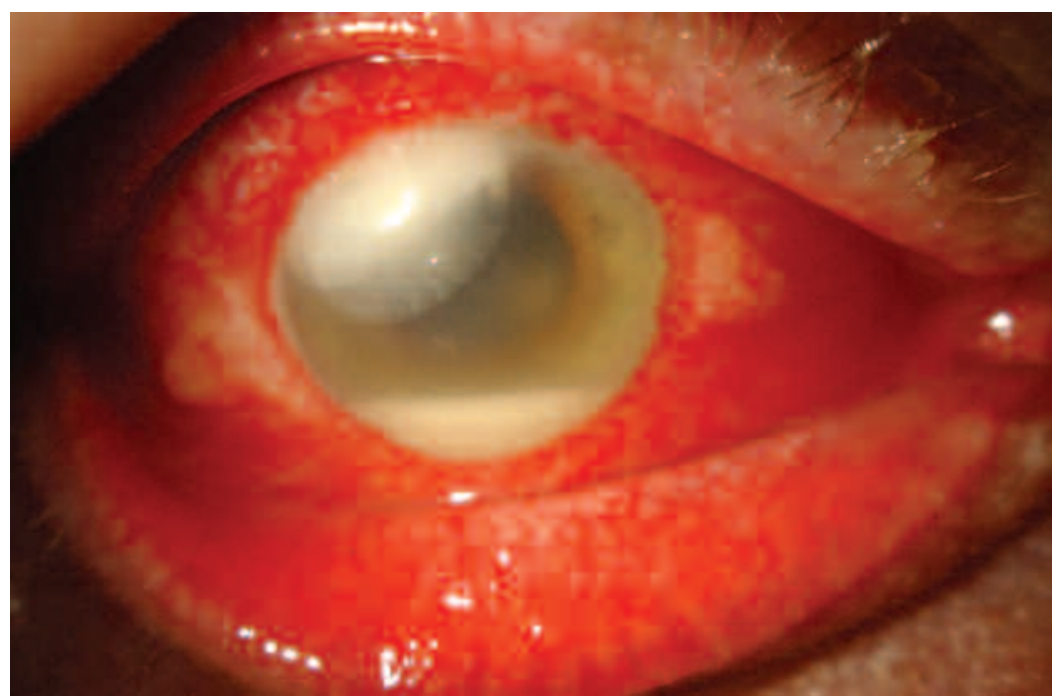

Figure 2. Slit-lamp examination of Patient 3. Endophthalmitis with hypopyon and corneal abscess spreading from the suture incision (upper right). 
Patient 2. A 64-year-old man had severe and active RA for 10 years. He had a history of hematochromatosis and congenital blepharoptosis of his right eye, which had been surgically treated in his childhood. As a result, he experienced difficulty closing his eye. MTX and leflunomide failed to control his RA. Treatment with adalimumab was started in May 2005 (40 mg every 2 wks) together with MTX and prednisone, followed by etanercept after 6 months ( $50 \mathrm{mg} / \mathrm{wk})$. Four months later, he suddenly complained of a painful red right eye, associated with photophobia and vision loss. He reported onset with subconjunctival hemorrhage 2 days before. Ophthalmological examination revealed a corneal ulceration with destruction of the eye. Neither analysis of vitreous culture nor histological examination were undertaken, but purulence of the eye was highly suggestive of infection. He had necrosis of the eye and no light visual acuity. Evisceration was performed, immediately followed by an ocular prosthesis in April 2006.

Patient 3. A 68-year-old man presented with a 6-year history of severe seropositive and erosive RA. His history included diabetes mellitus and cataract surgery in 1999 with suture of the corneal incision. Infliximab therapy was started in February 2002, associated with MTX 15 mg/week and prednisone $15 \mathrm{mg} /$ day. In March 2004, while receiving treatment with $4 \mathrm{mg} / \mathrm{kg}$ (300 mg)/6 weeks of infliximab, he suddenly complained of ocular discomfort. Ocular examination revealed inflammation of the corneal suture, which was removed. Two days later, the pain worsened and he noticed blurred vision. Examination revealed a deep corneal abscess and a hypopyon in the anterior chamber. Corneal scraping was performed and culture showed presence of Streptococcus pneumoniae. Despite antimicrobial therapy, he rapidly developed endophthalmitis (Figure 2). Outcome was unfavorable, with retinal detachment resulting in visual loss.

Endophthalmitis is an infection of the posterior segment of the eye that frequently results in loss of vision. In our 3 cases, the contamination was exogenous and occurred after the development of bacterial keratitis. Indeed, none of our patients demonstrated systemic infection, positive blood culture, or distant infection reminiscent of an endogenous origin. Bacterial keratitis is rare in the absence of predisposing factors such as ocular trauma, ocular surface diseases, or use of contact lenses ${ }^{9}$. In our first 2 cases, difficulty closing the eye resulted in exposure keratopathy; in the third case, infection occurred after the removal of a corneal suture. Moreover, bacterial keratitis is rarely complicated with endophthalmitis.

In a retrospective study of 300 cases of bacterial keratitis, Bourcier, et al found 2 cases complicated with endophthalmitis ${ }^{9}$. Scott, et al showed that this type of contamination was associated with corticosteroid use and immunodepression ${ }^{10}$. However, only 1 case of exogenous endophthalmitis has been reported in RA patients treated with corticosteroid or DMARD ${ }^{11}$. The potential role of anti-TNF- $\alpha$ therapy in the unfavorable and rapid development of infection in our 3 patients should thus be considered.

These 3 cases highlight the possible risk of exogenous endophthalmitis in patients being treated with TNF blockers. Thus, rheumatologists should consider asking for ophthalmological advice before beginning TNF- $\alpha$ treatment, at least in patients with a history of risk factors for bacterial keratitis or undergoing ocular surgery.
BENOIT LE GOFF, MD, Service de Rhumatologie; BERTRAND VABRES, MD, Service d'Ophtalmologie, Hôtel-Dieu, CHU Nantes, Nantes; ISABELLE COCHEREAU, MD, Service d'Ophtalmologie; BEATRICE BOUVARD, MD,Service de Rhumatologie; CEDRIC LAMIREL, MD, Service d'Ophtalmologie, CHU Angers, Angers; YVES MAUGARS, MD; JEAN-MARIE BERTHELOT, MD, Service de Rhumatologie, Hôtel-Dieu, CHU Nantes, 44093, Nantes Cedex 01, France. Address reprint requests to Dr. Le Goff.

E-mail: benoit.legoff@chu-nantes.fr

\section{REFERENCES}

1. Kresloff MS, Castellarin AA, Zarbin MA. Endophthalmitis. Surv Ophthalmol 1998;43:193-224.

2. Callegan MC, Engelbert M, Parke DW 2nd, Jett BD, Gilmore MS. Bacterial endophthalmitis: epidemiology, therapeutics, and bacterium-host interactions. Clin Microbiol Rev 2002;15:111-24.

3. Dixon WG, Watson K, Lunt M, Hyrich KL, Silman AJ, Symmons DP. Rates of serious infection, including site-specific and bacterial intracellular infection, in rheumatoid arthritis patients receiving anti-tumor necrosis factor therapy: results from the British Society for Rheumatology Biologics Register. Arthritis Rheum 2006; 54:2368-76.

4. Haerter G, Manfras BJ, de Jong-Hesse Y, et al. Cytomegalovirus retinitis in a patient treated with anti-tumor necrosis factor alpha antibody therapy for rheumatoid arthritis. Clin Infect Dis 2004;39:e88-94.

5. Roos JC, Ostor AJ. Orbital cellulitis in a patient receiving infliximab for ankylosing spondylitis. Am J Ophthalmol 2006;141:767-9.

6. Lassoued S, Zabraniecki L, Marin F, Billey T. Toxoplasmic chorioretinitis and antitumor necrosis factor treatment in rheumatoid arthritis. Semin Arthritis Rheum 2007;36:262-3.

7. Montero JA, Ruiz-Moreno JM, Rodriguez AE, Ferrer C, Sanchis E, Alio JL. Endogenous endophthalmitis by Propionibacterium acnes associated with leflunomide and adalimumab therapy. Eur J Ophthalmol 2006;16:343-5.

8. Agarwal PK, Gallaghar M, Murphy E, Virdi M. Endogenous endophthalmitis in a rheumatoid patient on tumor necrosis factor alpha blocker. Indian J Ophthalmol 2007;55:230-2.

9. Bourcier T, Thomas F, Borderie V, Chaumeil C, Laroche L. Bacterial keratitis: predisposing factors, clinical and micro biological review of 300 cases. Br J Ophthalmol 2003;87:834-8.

10. Scott IU, Flynn HW Jr, Feuer W, et al. Endophthalmitis associated with microbial keratitis. Ophthalmology 1996;103:1864-70.

11. Caravalho J Jr, McMillan VM, Ellis RB, Betancourt A. Endogenous endophthalmitis due to Salmonella arizonae and Hafnia alvei. South Med J 1990;83:325-7.

J Rheumatol 2009;36:1; doi:10.3899/jrheum.080236 